\title{
Current vulnerability in the Monte Alén-Monts de Cristal landscape, Equatorial Guinea
}

Pavageau, C., ${ }^{1}$ Coll Besa, M. ${ }^{2}$ and Morchain, D.

Between 2011 and 2012, a regional baseline assessment to analyse vulnerability was conducted in five landscapes of the Congo Basin as part of the 'Climate Change and Forests in the Congo Basin: Synergies between Adaptation and Mitigation (COBAM)' project. This briefing note summarises the results for the Monte Alén-Monts de Cristal landscape.

\section{Study site in the Monte Alén-Monts de Cristal landscape}

The Monte Alén-Monts de Cristal landscape covers a total of 26747 $\mathrm{km}^{2}$ across Gabon and Equatorial Guinea. The landscape comprises national parks, such as Monte Alén National Park and Al-tos de Nsork National Park, forest management units, national forests and traditional community land and villages. Despite the presence of three national parks and one national reserve, the economy and land use are dominated by industrial logging concessions, which account for $65 \%$ of the available land. However, since the discovery of large oil reserves in 1996, the income from oil has greatly exceeded that from timber and has shifted investor interest away from timber exploitation.

Laws in Equatorial Guinea have evolved towards a partial devolution of forest management to local communities. At present, traditional communities can claim rights on community forests through the title of bosques comunales, which replaces the title of reserva de poblados. Nevertheless, very few officially recognised bosques comunales are operational for forest exploitation in the area.

This study focused on one village in the landscape, Atom, which is located outside the protected areas, in the national forest domain in Centro Sur Province in the district of Evinayong.

\section{Participatory methodology}

The vulnerability assessment focused on current vulnerability, which includes an analysis of both past trends and present conditions. In particular, the analysis considers the social aspects of vulnerability,
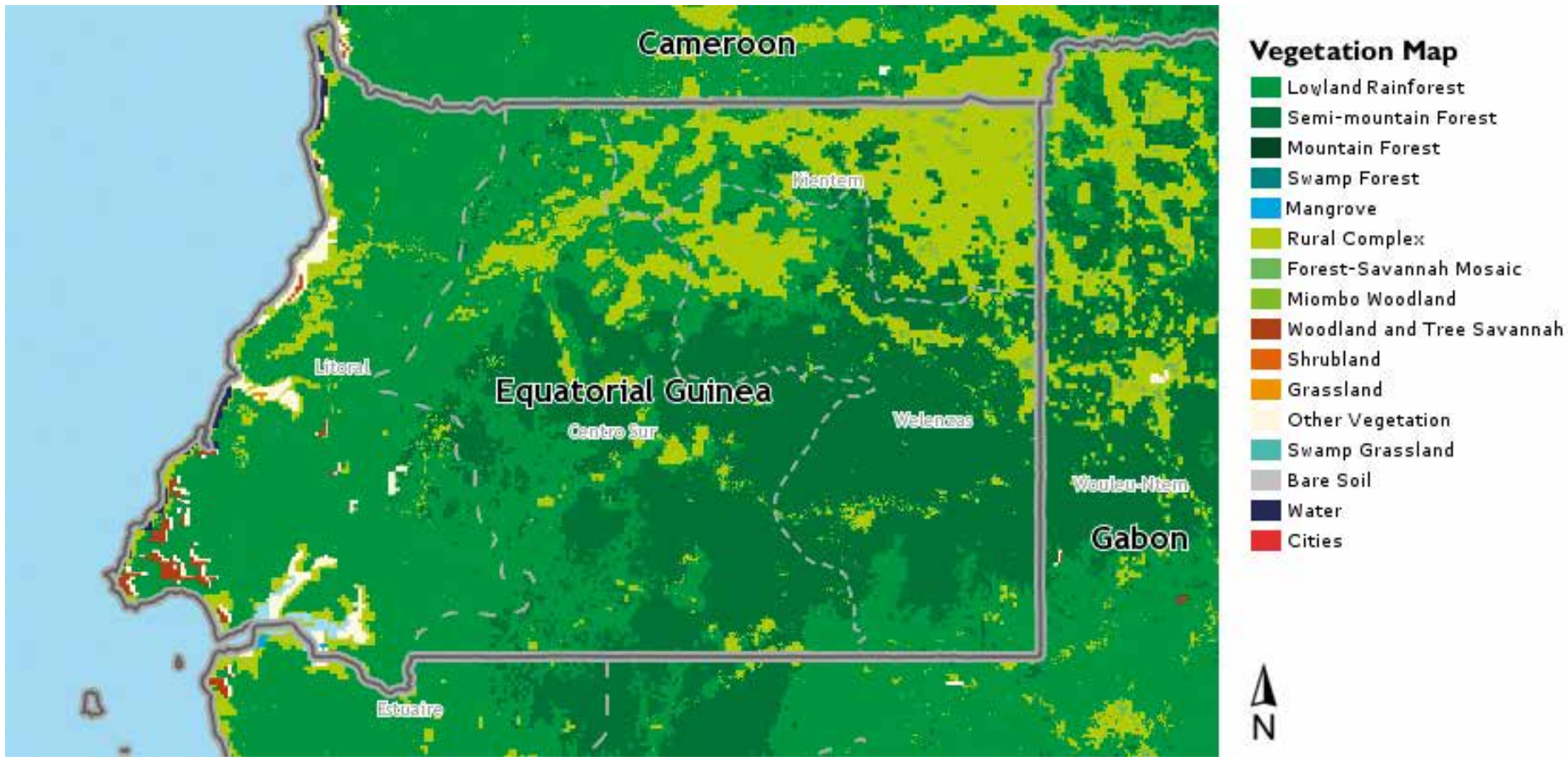

Figure 1. Location of the study site

Source: Globcover-UCL, GLC2000-JRC, South Dakota, compiled by OFAC regional centre (de Wasseige, C., Mfuka, C., Defourny, P., Mayaux, P., Hansen, M.) 
understanding it as processes rooted in the actions of human actors and their interactions with the natural resource base on which they depend. Different dimensions of vulnerability framed the assessment, which largely applied a participatory approach.

The different methods applied in the local communities were implemented in three phases: 1) preparatory phase, 2) workshop at district level and 3) fieldwork using participatory tools.

Methods included a literature review and focus group discussions with various participatory exercises.

\section{Local perceptions of change}

Villagers in the project site have witnessed major ecological and socio-economic changes in the past few decades. In particular, they have noticed trends of forest cover decline and decreasing population since the 1970s. Migratory outflows and limited access to markets create hardship for the communities (e.g. leading to shortage of farm labour and abandonment of certain crops). Furthermore, demand for land for agriculture has increased in recent decades, encouraging slash-and-burn shifting cultivation and the use of mature forest. Traditional cocoa plantations have been abandoned. In addition, a shift towards an oil economy in the past two decades has caused a decline in forestry activities and deforestation in the country. Villagers described a ban on hunting within protected areas and a complete ban on hunting primates as a particular injustice and barrier to their livelihood because forest animals damage their crops. The degradation of forests around the villages and the use of production systems that are heavily reliant on subsistence farming have made local livelihoods highly fragile, because of the scarcity of resources and the lack of alternative livelihoods. In addition, rainfall patterns are increasingly unpredictable.

An analysis of historical disturbances in the village reveals a strong preoccupation with the effect of climate-related events on local livelihoods. In particular, increases in temperatures, torrential rains, changes in the seasons and, to a lesser extent, strong winds

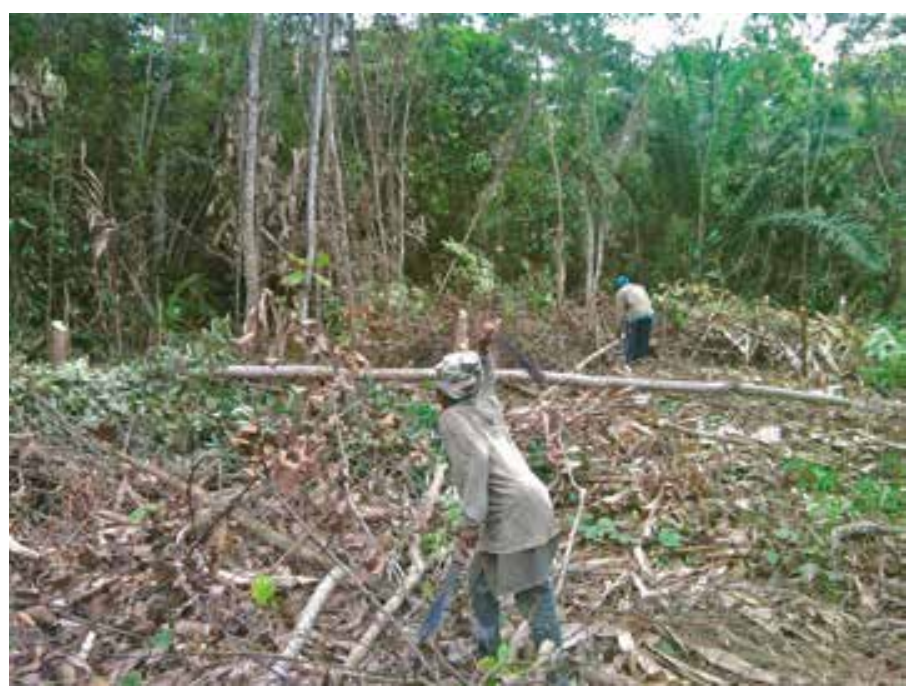

In the words of one farmer: 'Rain has become unpredictable and it has become difficult to plan when is the right time to clear land and plant.'

Photo: Guy Ngono have negative effects on the natural resource base and the local communities. Climate-related disturbances combine with multiple other threats to exacerbate the vulnerability of Atom village and the surrounding area.

\section{Differentiated vulnerability}

The analysis shows that different climate-related disturbances have different effects on different groups, natural resources and activities.

The availability of labour in a household is an important vulnerability factor. A family or household without enough available labour cannot perform certain farming activities on time and thus is more vulnerable to changes in the onset of seasons and may have fewer opportunities for livelihood diversification. In particular, female-headed households (e.g. widows) or households without active young people because of urban migration seem to be the most vulnerable social groups in the villages. Women are responsible for most agricultural tasks, whereas men predominantly engage in forest-related activities such as hunting.

Agriculture is the activity that is most exposed and affected by disturbances such as increased temperatures and changes in the seasons. Forest resources also are vulnerable, although to a lesser extent; in some cases, non-timber forest products (NTFPs) have benefited from changes in weather patterns. Villagers have noticed that they are no longer able to predict wet and dry periods and thus follow the 'traditional' production calendar for their activities. Increased climate variability and unpredictability of rainfall patterns have caused reductions in agricultural production, thus negatively affecting food security and the local economy.

\section{Vulnerability and production}

Transitions differ across the forest systems in the study area, which yield different products, as outlined in the table below.

The vulnerability of the natural systems and of the social groups that rely on them varies with the seasons. In the study area in Equatorial Guinea, each year has two cropping seasons, corresponding to the two rainy seasons, known as Oyon and Esseb (or Esep). During Esseb, two types of field are cultivated, compared with one during Oyon. Although Esseb therefore requires more labour, it also allows for greater diversification of crops. Furthermore, the crops cultivated in the different types of fields display differentiated sensitivity to climate variability.

The use of different types of fields suggests the use of rotation periods and the association of crops with different types of forest or fallows. In one type of agricultural field, groundnuts are cultivated, in association with cassava, cocoyam (Xanthosoma sagittifolium or malanga), maize and other vegetables. This type of field is harvested twice a year, during Esseb and Oyon. These fields are created in young fallows where branches and logs have decomposed and the land has been completely cleared. As the fertility of these soils decreases rapidly, these fields are only productive for one year.

In the second type of field, pumpkins (Cucumeropsis sp., used for its white seeds) or sugarcane are cultivated, in association with new cocoyam and cassava. These crops are planted in fields in mature forests or old secondary forests (therefore called forest fields) and are harvested only once a year (during Esseb). 
Table 1. Description of ecosystems used by the communities and products provided

\begin{tabular}{|c|c|c|c|c|}
\hline \multicolumn{5}{|l|}{ Forest transition } \\
\hline Name of ecosystem & Fe Bikoan & Bikoro & Mbut Afan or old Bikoro & Ngom Afan (dense forest) \\
\hline \multirow[t]{2}{*}{ Description } & $\begin{array}{l}\text { Cultivated areas } \\
\text { around houses } \\
\text { (gardens) }\end{array}$ & $\begin{array}{l}\text { Secondary forests shifting- } \\
\text { cultivation belt (includes } \\
\text { cultivated fields and fallows } \\
\text { at different stages) }\end{array}$ & \multirow[t]{2}{*}{$\begin{array}{l}\text { Transition forest between } \\
\text { bikoro and dense forest }\end{array}$} & \multirow[t]{2}{*}{$\begin{array}{l}\text { Primary forest, used as a land } \\
\text { reserve for agriculture and } \\
\text { other activities (e.g. hunting) }\end{array}$} \\
\hline & & $\begin{array}{l}\text { (A shifting cultivation plot } \\
\text { is called an ekoro.) }\end{array}$ & & \\
\hline \multirow[t]{6}{*}{ Examples of products } & Plantain & Cassava & \multirow{6}{*}{$\begin{array}{l}\text { Forest products (NTFPs, } \\
\text { wood) } \\
\text { Bushmeat }\end{array}$} & \multirow{6}{*}{$\begin{array}{l}\text { Forest products } \\
\text { (NTFPs, wood) } \\
\text { Bushmeat }\end{array}$} \\
\hline & Cassava & Groundnut & & \\
\hline & Pineapple & Plantain & & \\
\hline & Avocado & Maize & & \\
\hline & Coffee & Pumpkin & & \\
\hline & Cocoa & Bushmeat & & \\
\hline
\end{tabular}

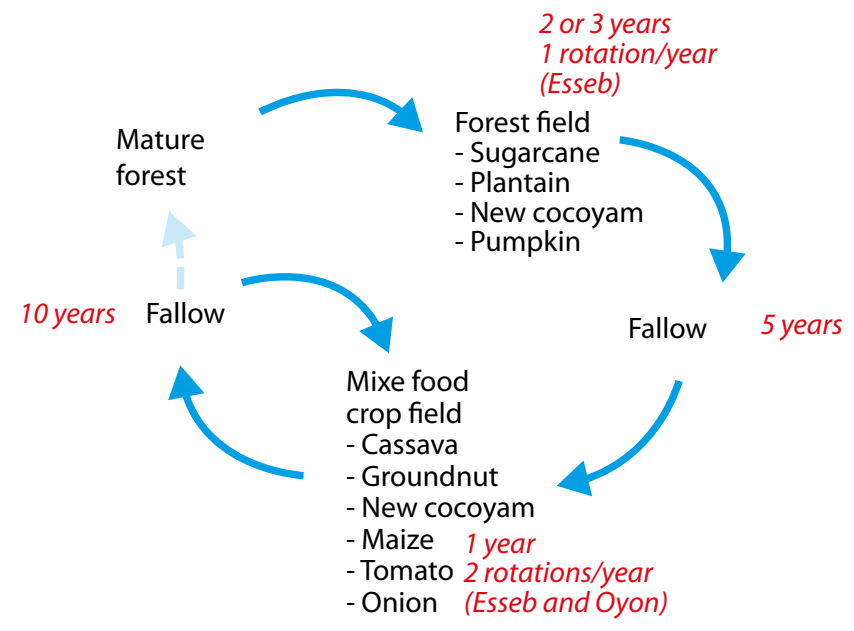

Figure 2. Dynamics of ecosystems and periods of rotation

\section{Current adaptive capacity}

Subsistence agriculture remains the main form of production. Traditional farming practices, particularly slash-and-burn shifting cultivation, are prevalent in the area.

The main food crops are cassava (the most important), plantain, groundnut, sugarcane and pineapple, and are usually cultivated in association. The production system is based on the valorisation of the different types of ecosystems (forest, fallows), which is linked to different associations of crops, management practices and distribution of the workload over the year. Therefore, the production system displays a certain level of flexibility to environmental changes. Manufacturing of sugarcane alcohol (malamba), collection of NTFPs and hunting and fishing supplement household incomes, to a limited extent.

Although the villagers do have some degree of diversification in their sources of income, the degradation of forest resources hinders their capacity to adapt. Their high reliance on agriculture for household food security combined with the pressure on forest resources, including bushmeat, limits the role of forests as a safety net. Villagers require viable economic alternatives to compensate for losses incurred due to restrictions imposed on use of the forest.

\section{Social capital}

Collective action in the village is relatively weak. Where it does occur, it is driven by either external agents or family members that have moved to a city. Village institutions mainly rely on traditional or informal forms of organisation. The main governance structure is the council of elders, and the chief of each clan is part of the village council.

Villagers are not familiar with the concept of community management of forest. There has been almost no establishment of new formal institutions, as generally occurs in similar contexts with the support of public policies and foreign actors such as forest community or cooperatives, mainly because of barriers to their development. The villages have experienced progressive migration waves from rural to urban centres. However, migrants have retained their ties to the village and thus must be considered actors in the village's social networks. Migration to cities has had important social consequences for the village and its social organisation. The role of migrants in the development of the village varies, but family members remaining in the village have high expectations of additional income in the form of remittances from migrants.

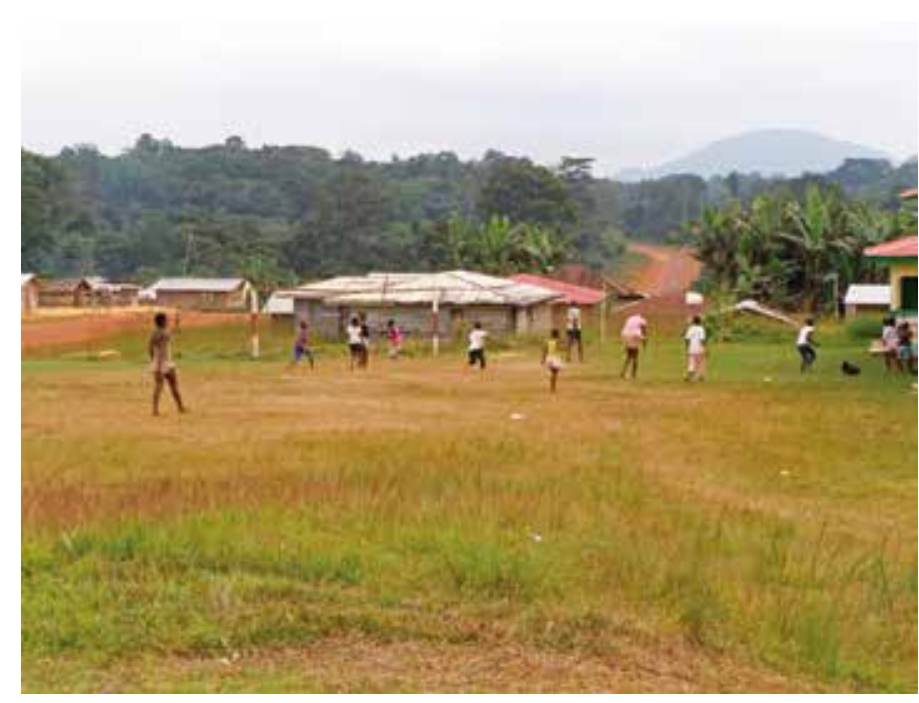

Children playing in Atom, Equatorial Guinea

Photo: Daniel Morchain 


\section{Looking ahead}

Lessons from past ecological and social dynamics serve as the basis for building adaptive capacity to climate variability. However, adaptation to future climate change requires building the capacity to adapt to new and unprecedented situations and events.

Consequently, planning for uncertainty must be a key element in any decisions. Strategies should be devised to expand safety nets through the construction of a broader livelihood base and greater access to options; to generate more information on social and ecological interactions; and to enhance collaboration between actors with different experiences and knowledge.

Given that agriculture is the main livelihood activity and puts pressure on forest resources, climate-smart agriculture options could be envisaged in the area. Such options include the use of conservation agriculture, the application of agroforestry principles and practices, and the cultivation of home gardens. The introduction of these practices could maximise agricultural yields, diversify production and improve overall household food security, and help maintain soil fertility and control soil erosion in the long run. Such practices could be promoted through planting of food crops in association with existing crops. However, the technical suitability and cultural sensitivities related to such practices should be further explored.

With Equatorial Guinea's current shift towards an oil economy, large investments are being made in infrastructure across the country. Therefore, efforts to enhance market linkages with rural areas and to provide training on techniques for processing, storage and commercialisation of food crops and NTFPs could lead to better quality of such products and greater competitiveness in urban markets. This becomes even more relevant given that migration to urban hubs has had important social consequences and many migrants remain actors in the village's social network.

Pilot activities, such as those supported by the COBAM project, could lay the foundations for longer-term solutions, as long as there is systematic learning that enables reflection and refinement along the way. This will require mechanisms to support the learning process and facilitate experimenting, monitoring and improving over time.

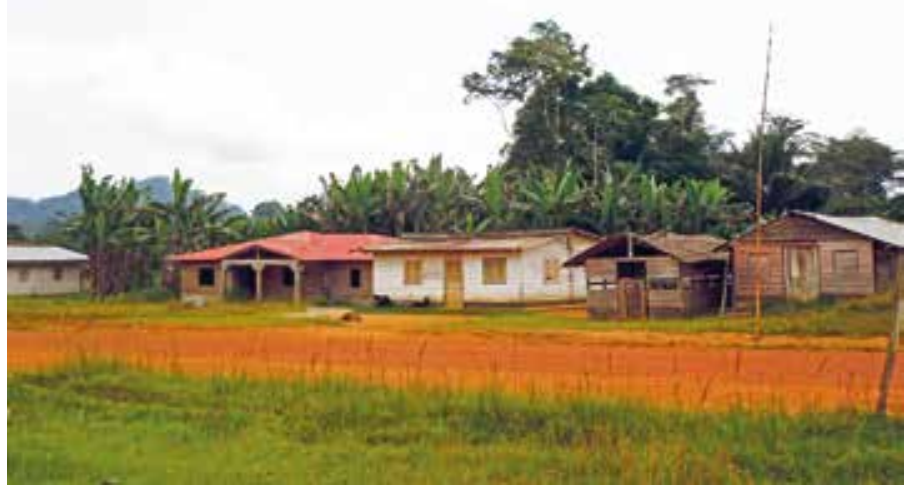

\section{Atom village in the Monte Alén-Monts de Cristal landscape}

Photo: Daniel Morchain

The insights generated by the vulnerability baseline assessment will be combined with more in-depth research to explore future vulnerability and identify synergies between mitigation and adaptation in the project sites. Results from further analyses and evaluation of future strategies will generate recommendations to inform decision-making and planning at local and national levels across countries in the Congo Basin.

\section{Acknowledgements}

The regional baseline assessment was implemented in collaboration with many partners. Researchers from the Stockholm Environment Institute (SEI) and the Center for International Forestry Research (CIFOR) worked closely with local partners in each site. In the case of the Monte Alén-Monts de Cristal landscape, we would like to thank Fidel Esono Mba (INDEFOR Executive Director), Diosdado Obiang Mbomio (Chief of the Department for Sustainable Forestry Development), Juan Abeso (Cartographic Technician-Project Assistant) and the team at INDEFOR for the support provided.
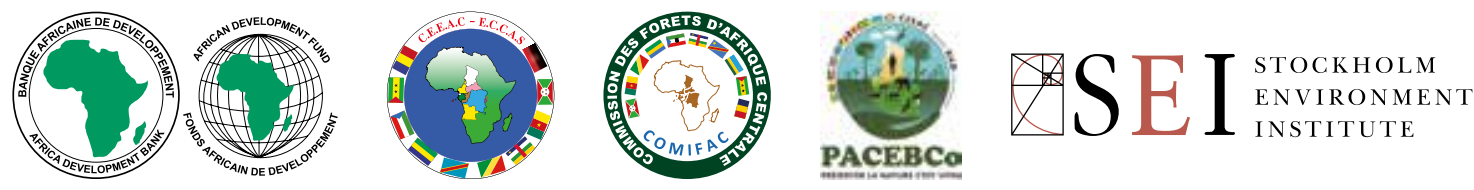

\section{cifor.org/cobam}

